\title{
Genetic diversity of Rhizopus microsporus from traditional inoculum of tempeh in Indonesia based on ITS sequences and RAPD marker
}

\author{
TATI BARUS`, RONALDO HALIM, ANASTASIA TATIK HARTANTI, PAULUS KEVIN SAPUTRA \\ Department of Biology, Faculty of Biotechnology, Universitas Katholik Atma Jaya. Jl. Jenderal Sudirman No. 51, Jakarta 12930, Indonesia. \\ Tel.: +62-21-5703306/5727615 ext. 450, Fax.: +62-21-5719060, `email: tati.barus@atmajaya.ac.id
}

Manuscript received: 4 October 2018. Revision accepted: 26 February 2019.

\begin{abstract}
Barus T, Halim R, Hartanti AT, Saputra PK. 2019. Genetic diversity of Rhizopus microsporus from traditional inoculum of tempeh in Indonesia based on ITS sequences and RAPD marker. Biodiversitas 20: 847-852. The main microorganism for tempeh fermentation is Rhizopus microsporus. These days, many tempeh producers use commercial inoculum, such as 'Raprima' as resource of $R$. microsporus. As a result, the genetic diversity of $R$. microsporus that had been reported in Indonesia has diminished. Information about genetic diversity is needed as a basis to select $R$. microsporus as tempeh inoculum. This research aims to investigate the genetic diversity of $R$. microsporus from waru leaves based on Internal Transcribed Spacer (ITS) Sequence and Random Amplified Polymorphic DNA (RAPD) markers. A total of 25 R. microsporus were isolated from traditional inoculum waru leaves (Inoculum 1) and traditional inoculum other than waru leaves (Inoculum 2). Amplification of ITS sequence was done using universal primer pairs of ITS-4 and ITS-5. Amplification of RAPD markers was done using primers OPC-08, OPC-19, OPQ-6, R-108, OPA-09 and OPJ-20. ITS sequence was not sufficient to compare the similarities among $R$. microsporus. On the other hand, RAPD markers successfully compared the similarities among $25 R$. microsporus. A total of $25 R$. microsporus were divided into 9 clusters. $R$. microsporus from Inoculum 1 grouped into Cluster 1, Cluster 3 and Cluster 4-8. Inoculum 2 grouped into Cluster 2 and Cluster 9. R. microsporus from tempeh grouped into Cluster 4 and was different from Inoculum 1 and Inoculum 2, except for TB3.
\end{abstract}

Keywords: Diversity, ITS sequence, RAPD marker, Rhizopus microsporus, tempeh

\section{INTRODUCTION}

Soybeans tempeh (tempeh) is a popular traditional food in Indonesia that is processed by fermenting soybeans. The most commonly used raw material for making tempeh is yellow seeded soybeans. Fermentation technology in the manufacture of tempeh has been handed down through generations and was changed based on experience. It is predicted to have originated from West Java-Indonesia as mentioned in Serat Centhini (1814) (Shurtleff and Aoyagi 2013).

Fermentation of soybeans into tempeh as food yield much superior nutritional value and positive aspects to health. Soybeans as raw form of tempeh contain approximately $40 \%$ protein, $35 \%$ carbohydrates, $20 \%$ fat, and 5\% ash (Liu 1997). Fermentation of soybeans into tempeh degrade these macromolecules into smaller units, so that it can easily be digested and utilized by the body (Nout and Kiers 2005). Denter et al. (1998) reported that the concentration of some vitamins, such as riboflavin, B12, niacin, pyridoxine, folic acid, and biotin are higher in tempeh compared within soybeans. Tempeh contains antibacterial compounds that can inhibit pathogenic bacterias (Roubos-van den Hil and Nout 2011) and antioxidants (Klus et al. 1993; Esaki et al. 1996). Furthermore, tempeh also might modulate the composition of gut microbiota toward a healthier gut and stimulate IgA secretion (Soka et al. 2014)).
The main microorganism in fermentation of tempeh is Rhizopus spp. Therefore, Rhizopus spp. have been known as one of the economically important molds in Indonesia. Currently, diversity of Rhizopus in tempeh has been reduced. Please write some sentence as reference of ITS. Thirty-five species (97\%) Rhizopus species have been isolated from tempeh obtained from 29 locations in Indonesia are $R$. microsporus which is genetically similar based on ITS sequence (Hartanti et al. 2015). This is due to the use of commercialized tempeh inoculum which is composed of particular species of Rhizopus, especially $R$. microsporus. Many Strains of Rhizopus spp. (Dolatabadi et al. 2014), $R$. oryzae, $R$. arrhizus (Abe et al. 2010), and $R$. stolonifer were previously reported in tempeh (Dwidjoseputro and Frederick 1970; Prihatna and Suwanto 2007). In the past, species of Rhizopus spp. for the manufacture of tempeh in Indonesia was highly varied because the tempeh producers use their own traditionally produced inoculums. Now, there are fewer tempeh craftsmen who still use traditional inoculum. Rhizopus spp. from the traditional inoculum has not been investigated yet. Identification of Rhizopus spp. has been done by comparing physiological and morphological features in the past (Schipper 1984; Schipper and Stalpers 1984). In the past, identification of Rhizopus spp. has been done by comparing physiological and morphological features (Schipper 1984; Schipper and Stalpers 1984). At present, many molecular techniques are available, generally based on sequence $18 \mathrm{~S}$ 
ribosomal DNA (rDNA), 28S rDNA and internal transcribed spacer (ITS) (Abe et al. 2006, 2007, 2010). However, ITS sequence is often used because of it is a conserved region in the fungal DNA and has a high mutation rate among species (Abe et al. 2003; Iwen et al. 2002; Lott et al. 1998). To compare the diversity within species, RAPD markers are often used and has been successful in comparing the genetic diversity of molds (Anggriawan 2017; Lusta et al. 2003). Rhizopus is a species of mold. Therefore, this study aims to assess the genetic diversity of Rhizopus species from traditional inoculums of tempeh. The results will be used as basis for further analysis of the role of Rhizopus species in determining the quality of the tempeh.

\section{MATERIALS AND METHODS}

\section{Isolation of Rhizopus species}

Rhizopus species were isolated from traditional inoculum from 18 samples of waru leaves (Inoculum 1), traditional inoculum other than waru leaves (Inoculum 2) and tempeh collected from Yogyakarta-Central JavaIndonesia. Each sample was suspended in sterile $0.85 \%$ w/v $\mathrm{NaCl}$ by the use of a Stomacher lab-blender 400 (Seward Medical, London, UK) for 1 minute at "normal" speed. Each Rhizopus species was grown on potato dextrose agar (PDA) and incubated at $28^{\circ} \mathrm{C}$ for 2 days. All obtained Rhizopus species were temporarily stored at $4{ }^{\circ} \mathrm{C}$ for further analysis.

\section{Growth of Rhizopus species at several temperature levels}

The growth of each Rhizopus species is examined at some temperature variations to know the maximum growth temperature. Therefore, each Rhizopus species was grown on PDA and incubated at $33{ }^{\circ} \mathrm{C}, 42{ }^{\circ} \mathrm{C}, 45^{\circ} \mathrm{C}$, and $48{ }^{\circ} \mathrm{C}$ (Hartanti et al. 2015).

\section{Isolation of 22 Rhizopus species genome}

A total of 22 Rhizopus species were identified based on conserved ribosomal internal transcribed spacer (ITS) region. Mycelium of each Rhizopus species grown on PDA has been used as DNA sources for genome isolation using Phytopure $^{\mathrm{TM}}$ DNA Extraction Kit (GE Healthcare, UK) according to the manufacturer's protocol. Genome isolation products were checked using $1 \%$ electrophoresis agarose gel (Promega, Madison, USA) then stained with ethidium bromide (Sigma-Aldrich, USA). UV transilluminator has been used to visualize DNA genome in gel electrophoresis.

\section{Sequence amplification of ITS}

The ITS regions between the small nuclear $18 \mathrm{~S}$ rDNA and large nuclear 28S rDNA were amplified, including 5.8S rDNA using universal primer pairs of ITS-4 (5'TCCTCCGCTTATTGATATGC-3') and ITS-5 (5'GGAAGTAAAAGTCGTAACAAGG-3') (White et al. 1990). Sequence amplification was conducted in GeneAmp® PCR System 2700 (Applied Biosystems, Carlsbad, CA, USA) with total $50 \mu \mathrm{L}$ reaction mixture containing $1.5 \mu \mathrm{L} 10 \mathrm{mM}$ dNTPmix; $1 \mu \mathrm{L}$ DNA template; $2.5 \mu \mathrm{L}$ each primer (each of ITS-4 and ITS-5); $10 \mu \mathrm{L} 5 \mathrm{X}$ KAPA Taq EXtra Buffer; $3.5 \mu \mathrm{L} \mathrm{MgCl}_{2} 25 \mathrm{mM} ; 28.5 \mu \mathrm{L}$ nuclease-free water (NFW); and $0.5 \mu \mathrm{L}(2.5 \mathrm{U} / \mu \mathrm{L}) \mu \mathrm{L}$ KAPA Taq EXtra HotStart DNA Polymerase.. The amplification cycle consists of an initial denaturation at $94{ }^{\circ} \mathrm{C}$ for 2 minutes followed by 35 cycles of denaturation at $94{ }^{\circ} \mathrm{C}$ for 15 seconds, annealing at a temperature of 55 ${ }^{\circ} \mathrm{C}$ for 30 seconds, and extension at $72{ }^{\circ} \mathrm{C}$ for 1 minute. Final elongation was set at $72{ }^{\circ} \mathrm{C}$ for 5 minutes. Amplified PCR products were checked on agarose gel $(1 \% \mathrm{w} / \mathrm{v})$ (Promega, Madison, USA) then stained with ethidium bromide (Sigma-Aldrich, USA). UV transilluminator was used to visualize the PCR products in gel electrophoresis.

\section{DNA sequencing of ITS region}

The PCR products were sequenced in Macrogen Inc., Republic of Korea. The ITS nucleotide sequences for each Rhizopus species were aligned with ITS sequence database provided by GenBank (www.ncbi.nlm.nih.gov) using Basic Local Alignment Search Tool (BLAST) (http: //blast.ncbi.nlm.nih.gov/Blast.cgi). A phylogenetic tree was created using Molecular Evolutionary Genetics Analysis 7 (MEGA7). The branch support was analyzed by 1000x bootstrap analysis.

\section{Molecular characterization using RAPD marker}

The genetic diversity of 32 Rhizopus species was analyzed using RAPD marker in this study. $R$. microsporus TB1-TB2 were isolated from tempeh. $R$. microsporus TB3TB12, TB14-TB15, TB16-TB22 were isolated from Inoculum 1. R. microsporus TB69-TB82 were isolated from Inoculum 2 and identified based on ITS sequences by Jodi (2017). Amplification of RAPD marker of each Rhizopus species was performed in GeneAmp® PCR System 2700 (Applied Biosystems, Carlsbad, CA, USA) using six primers (Table 1). RAPD amplification was conducted with total $25 \mu \mathrm{L}$ reaction mixture containing $1 \mu \mathrm{L}$ DNA template $(150 \mathrm{ng} / \mu \mathrm{L}) ; 12.5 \mu \mathrm{L}$ GoTaq green (Thermoscientific); $5 \mu \mathrm{L}$ each primer $(100 \mu \mathrm{g})$ and $6.5 \mu \mathrm{L}$ NFW. PCR amplification was performed as follows: initial denaturation at $93^{\circ} \mathrm{C}$ for 1 minute; followed by 45 cycles of denaturation at $93^{\circ} \mathrm{C}$ for 1 minute; annealing at $30^{\circ} \mathrm{C}$ or $34^{\circ} \mathrm{C}$ (Table 1) for 1 minute and extension at $72^{\circ} \mathrm{C}$ for 2 minutes. Final elongation was set at $72^{\circ} \mathrm{C}$ for 5 minutes.

Each PCR product was separated by electrophoresis at a constant voltage of $60 \mathrm{~V}$ for 50 minutes in $1 \mathrm{x}$ TAE (Tris Acetate EDTA) buffer and resolved on agarose gel $(1 \%$ w/v) stained with ethidium bromide. The gel was visualized in a UV-transilluminator and photographed in a Gel Doc system (Vilber ${ }^{\mathrm{TM}}$ ). The $1 \mathrm{~kb}$ ladders (Fermentas) was used as known molecular weight marker. The bands of RAPD marker were scored as 1 or 0 on the basis of presence and absence of bands to make binary data. Phylogenetic tree was constructed using the Free Tree program (Pavlicek et al. 1999) and was clustered by the Unweighted Pair Group Method with Arithmetic Mean (UPGMA) method. Dendrogram was visualized using Tree View X (Roderic D.M. Page) software. 
Table 1: Primers used to amplify RAPD marker of Rhizopus species

\begin{tabular}{llcl}
\hline \multicolumn{1}{c}{ Primer } & \multicolumn{1}{c}{ Sequence } & $\begin{array}{c}\text { Meltin } \\
\text { Temp. }\end{array}$ & Sources \\
\hline OPC-08 & $5^{\prime}$-TGGACCGGTG-3' & $34^{\circ}$ & Vagvolgyi et al. (2004) \\
OPC-19 & $5^{\prime}$-GTTGCCAGCC-3' & $34^{\circ}$ & Vagvolgyi et al. (2004) \\
OPQ-06 & $5^{\prime}$-GAGCGCCTTG-3' & $34^{\circ}$ & Vagvolgyi et al. (2004) \\
R-108 & 5'-GTATTGCCCT-3' & $30^{\circ}$ & Vagvolgyi et al. (2004) \\
OPA-09 & $5^{\prime}$-GGGTAACGCC-3' & $34^{\circ}$ & Mahmodi et al. (2014) \\
OPJ-20 & $5^{\prime}$-AAGCGGCCTC-3' & $34^{\circ}$ & Mahmodi et al. (2014) \\
\hline
\end{tabular}

\section{RESULTS AND DISCUSSION}

Identification of Rhizopus species based on ITS sequence

A total of twenty Rhizopus species from tempeh and Inoculum 1 were isolated and identified. To obtain the genome of all Rhizopus species, the Phytopure ${ }^{\mathrm{TM}}$ DNA Extraction Kit was used. ITS sequences were successfully amplified. Each PCR amplification of ITS sequences showed DNA fragments with single band at $700 \mathrm{bp}$. The representative PCR amplification sequences of ITS of Rhizopus species are shown in Figure 3. BLASTN results of the ITS sequence ( \pm 650 nucleotides) showed similarity with Rhizopus microsporus in the range of 99\%-100\% with E-value 0 . The ITS sequences of each $R$. microsporus was deposited in NCBI GenBank with accession numbers listed in Table 2.

\section{Diversity of Rhizopus species based on ITS sequence}

The phylogenetic tree based on ITS sequences was successfully created (Figure 2). However, the ITS sequence cannot show variation among species of $R$. microsporus. Phylogenetic tree grouped all of $R$. microsporus into one big cluster. Thus, ITS sequences cannot distinguish genetic diversity of $R$. microsporus up to the variation level.

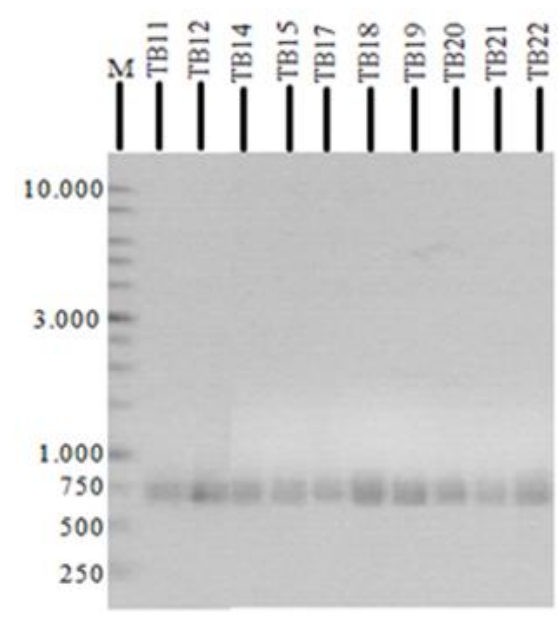

Figure 1: Results of PCR amplification sequences of internal transcribed spacer (ITS) as representative. M: Marker 1-kb ladder. TB11-TB12, TB14-B15, TB17-TB22: Rhizopus species were isolated from Inoculum 1.

Table 2: Isolate code, References species (GenBank), and GenBank accession numbers ITS sequences of Rhizopus species from tempeh and Inoculum 1.

\begin{tabular}{|c|c|c|}
\hline Isolate code & References species (GenBank) & $\begin{array}{c}\text { GenBank accession } \\
\text { numbers }\end{array}$ \\
\hline TB1 (tempeh) & R. microsporus var. oligosporus strain ATCC 22959 (KU729104.1) & MF445236 \\
\hline TB2 (tempeh) & R. microsporus var. oligosporus strain ATCC 22959 (KU729104.1) & MF445237 \\
\hline TB3 waru leaves & R. microsporus strain QTYC54 (KM103343.1) & MF445238 \\
\hline TB4 waru leaves & R. microsporus strain QTYC54 (KM103343.1) & MF445239 \\
\hline TB5 waru leaves & R. microsporus strain SHLSYD (KP340799.1) & MF445240 \\
\hline TB6 waru leaves & R. microsporus strain QTYC54 (KM103343.1) & MF445241 \\
\hline TB7 waru leaves & R. microsporus var. oligosporus strain ATCC 22959 (KU729104.1) & MF445242 \\
\hline TB8 waru leaves & R. microsporus var. oligosporus strain ATCC 22959 (KU729104.1) & MF445243 \\
\hline TB9 waru leaves & R. microsporus voucher KN2 (KU253769.1) & MF445244 \\
\hline TB10 waru leaves & R. microsporus strain QTYC54 (KM103343.1) & MF445245 \\
\hline TB11 waru leaves & R. microsporus strain QTYC54 (KM103343.1) & MF445246 \\
\hline TB12 waru leaves & R. microsporus strain SHLSYD (KP340799.1) & MF445247 \\
\hline TB14 waru leaves & R. microsporus strain QTYC54 (KM103343.1) & MF445249 \\
\hline TB15 waru leaves & R. microsporus strain SHLSYD (KP340799.1) & MF445250 \\
\hline TB16 waru leaves & R. microsporus strain QTYC54 (KM103343.1) & MF445252 \\
\hline TB17 waru leaves & R. microsporus strain QTYC54 (KM103343.1) & MF445252 \\
\hline TB18 waru leaves & R. microsporus strain SHLSYD (KP340799.1) & MF445253 \\
\hline TB19 waru leaves & R. microsporus strain QTYC54 (KM103343.1) & MF445254 \\
\hline TB20 waru leaves & R. microsporus strain QTYC54 (KM103343.1) & MF445255 \\
\hline TB21 waru leaves & R. microsporus strain QTYC54 (KM103343.1) & MF445256 \\
\hline TB22 waru leaves & R. microsporus strain SHLSYD (KP340799.1) & MF445257 \\
\hline
\end{tabular}




\section{Rhizopus microsporus growth in some temperature variations}

Each Rhizopus species was incubated to grow at $33{ }^{\circ} \mathrm{C}$, $42{ }^{\circ} \mathrm{C}, 45{ }^{\circ} \mathrm{C}$, and $48{ }^{\circ} \mathrm{C}$. The growth temperature of Rhizopus species varies. The results were shown that all Rhizopus species can grow up to $42^{\circ} \mathrm{C}$. There are eleven of Rhizopus species can grow up to $45^{\circ} \mathrm{C}$, but only seven (TB4, TB6, TB8, TB9, TB19, TB20, TB22) can grow up to $48^{\circ} \mathrm{C}$.

\section{Diversity of $\boldsymbol{R}$. microsporus based on RAPD analysis}

Dendrogram is shown as a representative of similarity among thirty-two isolates of Rhizopus species appear to form 9 clusters (Figure 3). Some of this $R$. microsporus have diverse genetic and some of them are not diverse, which can be seen by the position of the same isolates in the same cluster (Figure 3). Rhizopus from Inoculum 1 (Cluster 1, Cluster 3, Cluster 4-Cluster 8) seemed different than Rhizopus from Inoculum 2 (Cluster 2, Cluster 9). Rhizopus from tempeh (TB1 and TB2) was different from Rhizopus from Inoculum 1 and Inoculum 2, with the exception of TB3 which exist in the same group as TB 1 and TB2.

Table 3. RAPD marker amplification result using six different primers

\begin{tabular}{lccc}
\hline \multicolumn{1}{c}{ Primer } & $\begin{array}{c}\text { Formed } \\
\text { bands }\end{array}$ & $\begin{array}{c}\text { Polymorphic } \\
\text { bands }\end{array}$ & $\begin{array}{c}\text { Polymorphic } \\
\text { bands (\%) }\end{array}$ \\
\hline OPC-08 & 48 & 20 & \\
OPC-19 & 82 & 12 & \\
OPQ-06 & 58 & 35 & \\
R-108 & 50 & 11 & \\
OPA-09 & 89 & 2 & $17 \%$ \\
OPJ-20 & 126 & 0 & \\
Total & 453 & 80 & \\
\hline
\end{tabular}

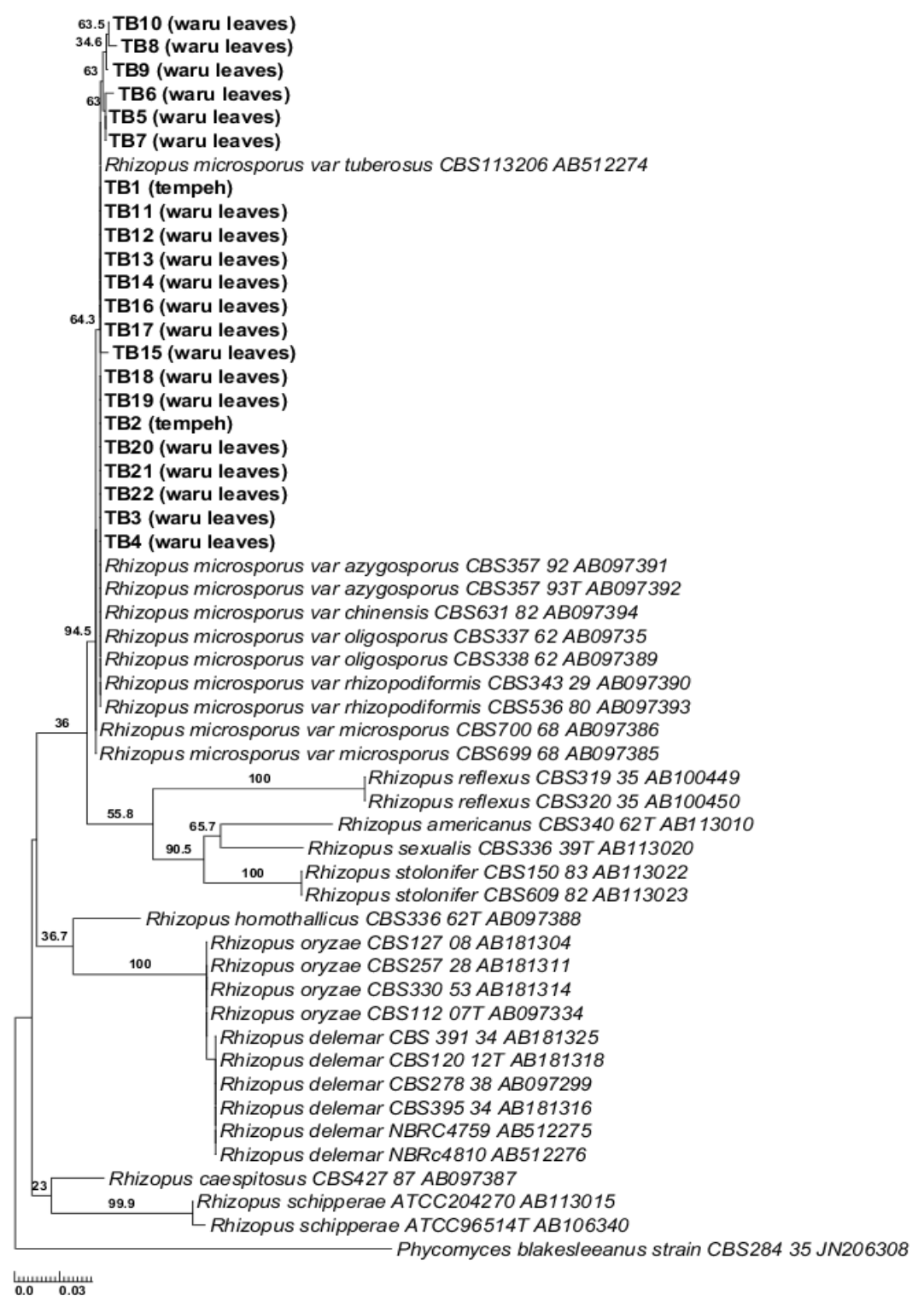

Figure 2: The phylogenetic tree of Rhizopus species from tempeh and inoculum I based on ITS sequences 


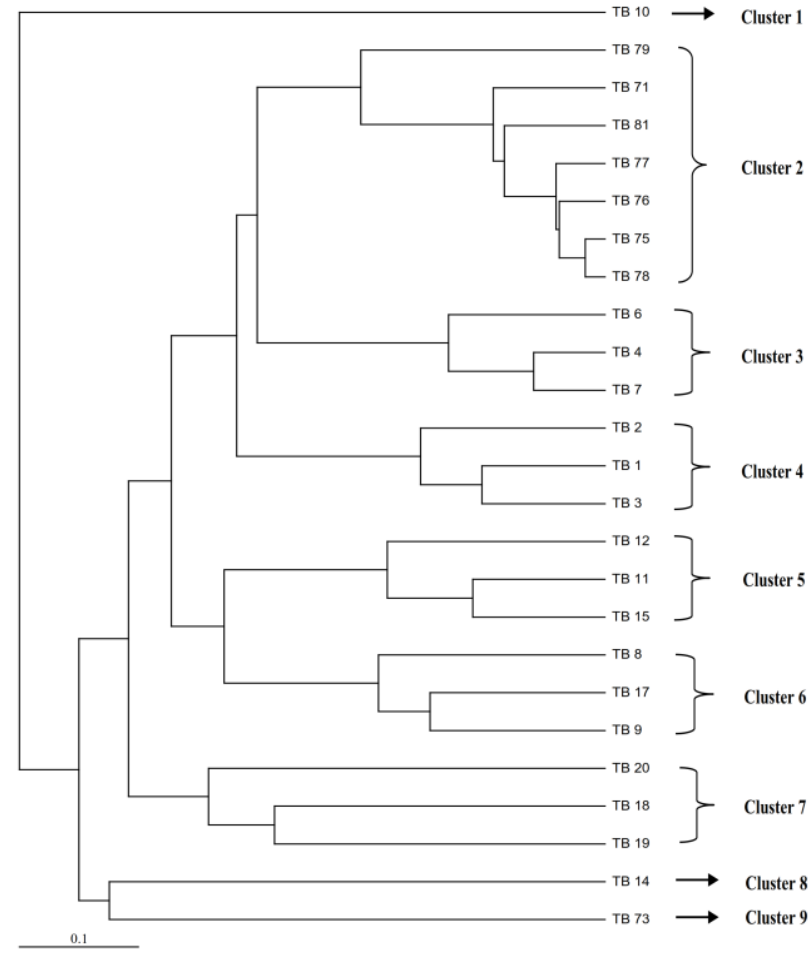

Figure 3. The phylogenetic tree of Rhizopus species constructed based on RAPD images. TB1-TB2 Rhizopus species from tempeh. TB3-TB12, TB14-TB15, TB16-TB22 Rhizopus species from Inoculum 1. TB 69-TB82 Rhizopus species Inoculum 2

\section{Discussion}

Tempeh is the original fermented food from Indonesia although it has been produced and consumed in various countries in the world. The quality of tempeh is determined by the technology, quality of soybeans used, and the microorganisms involved during the fermentation process. Rhizopus species is the main microorganism in making tempeh by fermentation process. Tempeh cannot be produced without involving Rhizopus spp. Since long ago, those species have been known as one of the economically important molds in Indonesia.

Barus et al. (2008) reported that tempeh is produced in uncontrolled fermentation conditions. Tempeh fermentation is still using conventional methods with uncontrolled condition. It has been reported that the taste of tempeh may vary due to the different types of microorganisms during fermentation. Particularly in the diversity between Rhizopus species and variations in the Rhizopus species. Previously reported that $R$. oligosporus, $R$. oryzae, $R$. arrhizus, and $R$. stolonifer were found in tempeh fermentation (Dwidjoseputro and Frederick 1970; Prihatna and Suwanto 2007). Hartanti et al. (2015) reported that tempeh was taken from 28 locations spread in Indonesia only contains $R$. microsporus. It has been reported that $R$ oligosporus is synonym of $R$. microsporus (Dolatabadi et al. 2014). However, Rhizopus species isolated from traditional inoculum of tempeh has not been reported. Thus, Rhizopus species from traditional inoculums waru leaves needs to be preserved and further investigated in determining the quality of tempeh. The results obtained in this study will be further used as a base for further analysis of R.microsporus in determining the quality of the tempeh.

Genome of each species of R.microsporus was isolated. One of the difficulties in studying fungi molecularly is in the process of genome extraction. In this study, extraction using Phytopure ${ }^{\mathrm{TM}}$ DNA Extraction Kit (GE Healthcare, UK) according to the manufacturer's protocol found no difficulty and the obtained genome quality was good. Based on the BLASTN results of ITS sequence, Rhizopus TB1-TB12, TB14-TB15, TB16-TB22 were isolated from Inoculum 1 in this study were identified as $R$. microsporus by Saputra (2017). Rhizopus TB 69-TB82 were isolated from traditional inoculum not waru leaves (Inoculum 2) were identified also as $R$. microsporus. Iwen, et al. (2002) reported that ITS sequences have become important molecular targets for identification of fungal. The ITS domains are more suitable for species identification than the $18 \mathrm{~S}$ region (small subunit), the $5.8 \mathrm{~S}$ region, and the $28 \mathrm{~S}$ region (large subunit) due to greater sequence variation (Iwen, et al. 2002; Lott et al. 1998). However, ITS sequence was not sufficient to show genetic diversity of $R$. microsporus into variation level. This can be seen from the phylogenetic tree (Figure 2) as an example. There are $R$. microsporus var. oligosporus, $R$. microsporus var. azygosporus, $R$. microsporus var. chinensis, and $R$. microsporus var. microsporus are still remained on one cluster.

The amplification of RAPD marker (Figure 3) with six primers produced diversity in DNA patterns of RAPD marker with size ranging from $70 \mathrm{bp}$ to $4000 \mathrm{bp}$. The phylogenetic tree as a representation of the genetic diversity of 25 Rhizopus species showed that thirty-two isolates of Rhizopus species appear to form 9 clusters (Figure 3). Some R. microsporus have diverse genetic and some of them are not diverse, which the position of the same isolates have been shown in the same cluster. It has been reported that RAPD -PCR technique can be used as an important tool for the genetic differentiation of fungal such as Fusarium species (Bonde et al. 2013; Haghighi and Shahdoust 2014). In this study, RAPD marker can also distinguish the genetic diversity of Rhizopus species which cannot be distinguished by the ITS sequences (Figure 2). There was no relation between genetic diversity and growth temperature of $R$. microsporus. Genetic $R$. microsporus of tempeh generally looks different with $R$. microsporus of Inoculum 1 and Inoculum 2.

The selection of primer used in PCR-RAPD marker is necessary. Some primers can produce many variations of the RAPD marker but some also are unsuccessful in generating RAPD marker variations. In this study, the highest variations in RAPD marker resulted from primers OPQ-06 (43 polymorphic) and OPC-08 (20 polymorphic), OPC-19 (12 polymorphic) patterns, respectively, while lowest variations resulted from primer of OPA-09 (2 polymorphic).

One of the important sources of protein for Indonesians is tempeh. The survey results indicate that each person on 
average consumes tempeh three times a week. Therefore, the results of this investigation are important as a basis for the selection of $R$. microsporus for further investigation of its role in determining the quality of tempeh.

\section{ACKNOWLEDGMENTS}

This study was supported by Competitive Grant Program from Atma Jaya Catholic University, Jakarta, Indonesia.

\section{REFERENCES}

Abe A, Sone T, Sujaya IN, Saito K, Oda Y, Asano K, Tomita F. 2003. rDNA ITS sequence of Rhizopus oryzae: its application to classification and identification of lactic acid producers. Biosc Biotechn Biochem 67 (8): 1725-1731.

Abe A, Oda Y, Asano K, Sone T. 2006. The molecular phylogeny of the genus Rhizopus based on rDNA sequences. Biosc Biotechn Biochem 70: 2387-2393.

Abe A, Oda Y, Asano K, Sone T. 2007. Rhizopus delemar is the proper name for fumaric malic acid producers. Mycologia 99: 714-22.

Abe A, Asano K, Sone T. 2010. A molecular phylogeny based taxonomy of the genus Rhizopus. Biosci Biotechnol Biochem 74: 1325-31.

Anggriawan R. 2017. Microbiological and food safety aspects of tempeh production in Indonesia [Dissertation]. Faculty of Agricultural Sciences, Georg-August-University, Gottingen.

Barus T, Suwanto A, Wahyudi AT, Wijaya H. 2008. Role of bacteria in tempe bitter taste formation: microbiological and molecular biological analysis based on 16S rRNA gene. Microbiol Indonesia 2: 17-21.

Denter J, Rehm HJ, Bisping B. 1998. Changes in the contents of fatsoluble vitamins and provitamins during tempe fermentation. J Food Microbiol 45: 129-134.

Walther G, van den Ende AH, deHoog GS. 2014. Diversity and delimitation of Rhizopus microsporus. Fungal Divers 64: 145-63.

Dwidjoseputro D, Frederick TW. 1970. Microbiological studies of Indonesian fermented foodstuffs. Mycopathol Mycol Appl 41: 21122.

Esaki H, Onozaki H, Kawakishi S, Osawa T. 1996. New antioxidant isolation from Tempe. J Agric Food Chem 44: 696-700.

Haghighi MT, Shahdoust E. 2014. Molecular analysis of genetic diversity of endophytic Myrothecium spp. by RAPD and ISSR markers. Intl J Sci Inven Today 3 (6): 692-704.

Hartanti AT, Rahayu G, Hidayat I. 2015. Rhizopus species from fresh tempeh collected from several regions in Indonesia. Hayati J Biosci 22 (1): 136-142.
Iwen PC, Hinrichs SH, Rupp ME. 2002. Utilisation of the internal transcribed spacer regions as molecular targets to detect and identify human fungal pathogens. Med Mycol 40: 87-109.

Klus K, Börger-Papendorf G, Barz W. 1993. Formation of 6,7,4 trihydroxyisoflavone (factor 2) from soybean seed isoflavones by bacteria isolated from tempe. Phytochemistry 34: 979-981.

Liu K. 1997. Soybeans: Chemistry, Technology, and Utilization. International Thomson Publishing, New York.

Lott TJ, Burns BM, Zancope-Oliveira R, Elie CM, Reiss E.1998. Sequence analysis of the internal transcribed spacer 2 (ITS2) from yeast species within the genus Carzdidu. Curr Microbiol 36: 63-69.

Lusta KA, Kochkina GA, Sul IW, Chung IK, Park HS, Shin D. 2003. An integrated approach to taxonomical identification of the novel filamentous fungus strain producing extracellular lipases: morphological, physiological and DNA fingerprinting techniques. Fungal Div 12: 135-149.

Mahmodi F, Kadir JB, Puteh A, Pourdad SS, Nasehi A, Soleimani N. 2014. Genetic diversity and differentiation of Colletotrichum spp. isolates associated with Leguminosae using multigene loci, RAPD and ISSR. Plant Pathol J 30 (1): 10-24.

Nout MJR, Kiers Jl. 2005. Tempe fermentation, innovation, and functionality: update into the third millennium. Appl Environ Microbiol 98: 789-805.

Pavlicek A, Hrdá S, Flegr J. 1999. Free-tree-freeware program for construction of phylogenetic trees on the basis of distance data and bootstrap/jackknife analysis of tree robustness. Application in the RAPD analysis of genus Frenkelia. Folia Biol 45 (3): 97-99.

Prihatna C, Suwanto A. 2007. Phenotypic, metabolic, and genetic diversity of the Indonesian strains of Rhizopus oligosporous. J Microbiol Indonesia 1: 27-32.

Roubos-van den Hil PJ, Nout MJR. 2011. Anti-diarrhoeal aspects of fermented soya beans. IntechOpen Limited, London.

Jodi. 2017. Keragaman Genetik Rhizopus spp. dari Laru Tradisional (Daun Waru) dan Tempe. [Hon. Thesis]. Faculty of Biotechnology, Atma Jaya Catholic University, Jakarta. [Indonesian]

Schipper MAA, Stalpers JA. 1984. A revision of the Genus Rhizopus. 2. The Rhizopus microsporus group. Stud Mycol 25: 20-34.

Schipper MAA. 1984. A revision of the Genus Rhizopus. 1. The Rhizopus stolonifer group and Rhizopus oryzae. Stud Mycol 25: 1-19.

Shurtleff W, Ayoagi A. 2013. History of whole dry soybeans, used as beans or ground, mashed or flaked. Soyinfo Center, Lafayette, USA.

Soka S, Suwanto A, Sajuthi D, Rusmana I. 2014. Impact of tempeh supplementation on gut microbiota composition in Sprague-Dawley rats. Res J Microbiol, 9 (4): 189-198.

Vagvolgyi C, Heinrich H, Ács K, Papp T. 2004. Genetic variability in the species Rhizopus stolonifera, assessed by random amplified polymorphic DNA. Antonie van Leeuwenhoek 86: 181-188.

White TJ, Bruns T, Lee S, Taylor J. 1990. Amplification and direct sequencing of fungal ribosomal RNA genes for phylogenetics. In: Innis MA, Gelfand DH, Sninsky JJ (eds.). PCR Protocols: A Guide to Methods and Applications, Academic Press Inc., New York. 